Artigo recebido em

20/09/2014

Aprovado em

27/10/2014

MARCOS

AMÉRICO

UNESP - Universidade

Estadual Paulista "Júlio de

Mesquita Filho"

- tuca@faac.unesp.br

Docente do Departamento de Comunicação Social

e do Programa de Pósgraduação em Televisão

Digital: Informação e

Conhecimento; Líder

do GECEF - Grupo de

Estudos em Comunicação

Esportiva e Futebol;

Mestre em Comunicação

(UNESP) e Doutor em

Educação para a Ciência

(UNESP).
Estudos em Jornalismo

e Mídia

Vol. $11 \mathrm{~N}^{\circ} 2$

Julho a Dezembro de 2014

ISSNe 1984-6924

\section{O Jornalismo Esportivo Transmídia no Ecossistema dos Esportes Eletrônicos (E-Sports)}

Marcos Américo

\section{Resumo}

O objetivo deste trabalho é discutir o conceito de e-sport ou esporte eletrônico na atividade jornalística esportiva no contexto transmídia. Para tanto são propostas reflexões sobre o conceito atual de esporte, a forte presença da game cultura na sociedade contemporânea e suas implicações no ecossistema midiático através da apresentação de uma plataforma on-line para esportes eletrônicos, denominada Twitch. Esta discussão passa a habitar um novo ecossistema midiático criado na esfera interdisciplinar que engloba esporte, sociologia, mídia e tecnologia. Neste ambiente, esportes e videogames fundem-se no conceito de e-sport (ou esporte eletrônico), um fenômeno da cultura digital contemporânea.

Palavras-chave

Jornalismo Transmídia, Jornalismo Esportivo, Mídia, Tecnologia.

\begin{abstract}
The purpose of this paper is to discuss the concept of e-sports (or electronic sports) in sports journalism in transmedia context. To achieve this goal are performed reflections on the current concept of sport, the strong presence of game culture in contemporary society and their implications in the media ecosystem through the presentation of an on-line platform for electronic sports, called Twitch. This thread moves into a new media ecosystem created in interdisciplinary sphere that encompasses sports and media \& technology. In this environment sports and video games seek merge into the concept of e-sport (electronic sport), a phenomenon of contemporary digital culture.
\end{abstract}

Keywords

Transmedia Journalism, Sports Journalism, Media, Technology. 


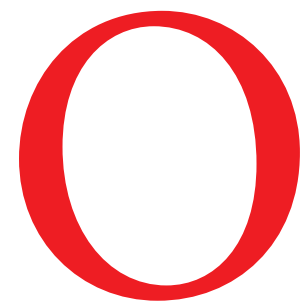

ambiente criado pelas Tecnologias da Informação e Comunicação (TIC) e o surgimento de áreas de estudos como a "Ecologia da Mídia”, definida por Nystrom (documento eletrônico) como "o estudo dos sistemas complexos de comunicação como meio-ambiente", apontam para o desenvolvimento de um novo habitat humano, imerso em informação cuja finalidade é prover, de maneira ubíqua, os usuários de informações, produtos e serviços que facilitem as atividades humanas. O universo criado pela popularização dos dispositivos informáticos, o acesso em banda larga ao mundo virtual da web, aliado ao surgimento de uma geração digital e on-line prevista por Tapscott (1999), cria novos paradigmas de comportamentos humanos e se percebe, principalmente na produção de bens simbólicos, novas formas de relações comunicacionais apoiadas na interatividade, atributo que esgota o "modelo fabril de comunicação baseado na lógica da distribuição" (SILVA, 2000, documento eletrônico) e que altera o esquema clássico da comunicação funcional fundamentado no trinômio emissão-mensagem-recepção. Surge assim um deslocamento do foco de atenção em direção à recepção e, "nos termos da comunicação interativa reconhece-se o caráter múltiplo, complexo, sensorial, participativo do receptor, o que implica em conceber a informação manipulável, como intervenção permanente sobre os dados" (SILVA, 2000, documento eletrônico). Portanto, as mídias digitais revolucionaram a indústria da informação e entretenimento, proporcionando um novo paradigma em suas formas de recepção onde os videogames e a game cultura reafirmam a ideia proposta pelo sociólogo Jo- han Huizinga em sua obra seminal "Homo Ludens" (1939) de que existe na sociedade um "espírito de jogo" presente em nossas atividades, desde as mais simples até as mais relevantes.

\section{Ecologia dos Meios}

Que a Comunicação também faça uso da metáfora ecológica não deve causar espanto. A história da humanidade confunde-se com a história do aparecimento de novas mídias comunicacionais. Começando com a invenção das escritas e do alfabeto, continuou com a prensa manual e, depois mecânica, com a fotografia, $o$ telégrafo, o jornal, o telefone, o cinema, o rádio, a TV etc. A constituição progressiva de uma ecologia midiática salta à vista. Tanto é assim que, com crescente frequência, o campo da Comunicação está fazendo uso da palavra "ecologia" e da descrição dos seus processos para autocaracterizar-se. (SANTAELLA, 2010, p.15).

Conforme Scolari (2012, p. 204-205), os estudos no campo da Ecologia da Mídia tiveram início nos anos 60 do século XX e foram, a princípio, ignorados pela comunidade científica. A criação da $\mathrm{Me}$ dia Ecology Association ${ }^{1}$ (1998), a acelerada expansão da internet e o consequente desenvolvimento dos processos de convergência digital ressuscitaram não somente o interesse em uma abordagem integrada da mídia, mas também as ideias de pensadores como Marshall McLuhan. Estes fatos consolidaram institucionalmente a Ecologia da Mídia no contexto dos estudos da Comunicação e das Ciências Sociais. Scolari ainda destaca Strate (2008, p. 130) que afirma que ainda que McLuhan tenha apresentado um importante papel na constituição deste campo de pesquisa, a Ecologia da Mídia "é muito mais que um Mcluhanismo"2.

Neste sentido, poderíamos dizer que muitos pesquisadores foram 
'McLuhanianos" antes de Mcluhan, da mesma forma que muitos escritores foram Kafkanianos antes de Kafka. Como podemos notar, a ecologia da mídia tem suas raízes mais profundas nas pesquisas desenvolvidas no século 20 nas áreas de economia, história, linguística, sociologia e educação. Os próprios Ecologistas da mídia se consideram situados dentro desta tradição multidisciplinar, criando assim um quadro teórico retroativo que suporte suas investigações contemporâneas.

(SCOLARI, 2012, p.205) ${ }^{3}$

Ainda de acordo com os apontamentos de Scolari, existem dúvidas ao redor do surgimento da metáfora "Ecologia da Mídia". Embora o termo tenha sido registrado por Neil Postman em uma conferência no National Council of Teachers of English (1968), o próprio autor reconheceu posteriormente que McLuhan havia empregado o conceito anos antes em uma comunicação pessoal e é possível considerar que a perspectiva ecológica da mídia estivesse presente nas discussões realizadas por aquele grupo de estudiosos da década de 1960. Atualmente podemos compreender a Ecologia dos Meios a partir de três conceituações mais presentes na literatura, a saber: (1) Postman (1980), que afirma que a Ecologia dos Meios "examina como os meios de comunicação afetam a percepção humana, a compreensão, o sentimento e os valores; e como nossa interação com a mídia facilita ou dificulta as nossas chances de sobrevivência"; (2) Strate (1999) a define como "o estudo de ambientes midiáticos, a ideia de que técnicas e tecnologias, formas de comunicação e códigos comunicacionais desempenham um importante papel nas relações humanas"; e (3) a mais sintética, proposta por Nystrom (1973), que entende a Ecologia dos Meios como "o estudo de sistemas complexos de comunicação como ambientes".

\section{Jornalismo Esportivo Transmídia}

A interatividade altera de forma sensível a atividade jornalística que se aproxima da narrativa transmídia e cria o jornalismo transmídia, definido por Renó \& Renó (2013, p. 62) como "uma forma de linguagem jornalística que contempla ao mesmo tempo distintos meios com várias linguagens e narrativas a partir de inúmeros meios e para uma infinidade de usuários".

Os mesmos autores afirmam que

A diferença do jornalismo transmídia sobre as outras formas de narrativas jornalísticas está na narrativa, que adota uma linguagem contemporânea, onde a mobilidade e a liquidez de estruturas, ou seja, a interatividade, assumem papéis importantes, como o de envolver e atrair o receptor para a interpretação participativa da mensagem, assim como sua transformação. Esse ponto - a expansão da narrativa a partir da interatividade - é um dos pontos fundamentais que podemos perceber. (RENÓ \& RENÓ, 2013, p. 62)

Dentro da especificidade do jornalismo esportivo, a narrativa transmídia já era potencializada mesmo antes do advento da digitalização e convergência dos meios. Um fato esportivo, desde muito, é uma narrativa que "contempla ao mesmo tempo distintos meios com várias linguagens e narrativas a partir de inúmeros meios e para uma infinidade de usuários" como afirmam acima Renó \& Renó (2013, p. 62). Basta imaginar um cenário pré-digitalização midiática: os fatos esportivos semanais se configuravam em narrativas que se iniciavam com a expectativa do próximo evento em jornais e rádios, continuavam nas transmissões ao vivo em emissoras de 
rádio e televisão e mesas-redondas pós-jogo e se desdobravam na repercussão em jornais, radiojornais, telejornais e revistas pós-evento com comentários inclusive nas redes sociais "boca-a-boca", para logo em seguida o ciclo novamente reiniciar. Desta forma, o jornalista ou repórter esportivo possui proximidade com este tipo de narrativa tão presente no ambiente digital e entende, quase que intuitivamente, que "uma história transmidiática se desenrola através de múltiplos suportes midiáticos, com cada novo texto contribuindo de maneira distinta e valiosa para o todo. Na forma ideal de narrativa transmidiática, cada meio faz o que faz de melhor" (JENKINS, 2008, p. 135). Diante do ambiente tecnológico que se configura, cabe aos jornalistas esportivos refletirem sobre possibilidades de coberturas jornalísticas assim como novas e polêmicas modalidades (de jogos e esportes) que surgem com a convergência digital e que provocam a recuperação das discussões sobre o próprio conceito de esporte e suas variações como jogos e esportes eletrônicos, objetos deste trabalho.

\section{Jogo e Esporte}

Para Huizinga (2000), designar a espécie humana como Homo sapiens (o ser racional) ou Homo faber (o que fabrica objetos - característica não somente dos humanos) não são definições que expressam nossa complexidade. Sugere, portanto, a incorporação da expressão Homo ludens (título de seu livro) à nossa nomenclatura e afirma que o jogo é um elemento da cultura humana. Desta forma, o autor toma o jogo "como fenômeno cultural e não biológico, e é estudado em uma perspectiva histórica, não propriamente científica em sentido restrito" (HUIZINGA, 2000, p.3). Discorre, ainda, com propriedade, sobre a natureza e o significado do jogo e o define como:

(...) uma atividade de ocupação voluntária, exercida dentro de certos e determinados limites de tempo e de espaço, segundo regras livremente consentidas, mas absolutamente obrigatórias, dotado de um fim em si mesmo, acompanhado de um sentimento de tensão e de alegria e de uma consciência de ser diferente da 'vida cotidiana'. (HUIZINGA, 2000, p. 33)

Outro autor que se debruçou sobre o tema dos jogos foi o intelectual francês Roger Caillois (1913-1978) que em 1967 escreveu "Os jogos e os homens". A definição proposta por Caillois aproxima-se de forma intensa àquela proposta por Huizinga e considera o jogo como uma atividade: 1- livre: uma vez que, se o jogador fosse a ela obrigado o jogo perderia de imediato a sua natureza de diversão atraente e alegre;

2- delimitada: circunscrita a limites de espaço e de tempo, rigorosa e previamente estabelecidos.

3- incerta: já que o seu desenrolar não pode ser determinado nem o resultado obtido previamente, e já que é obrigatoriamente deixada à iniciativa do jogador uma certa liberdade na necessidade de necessidade de inventar;

4- improdutiva: porque não gera nem bens, nem riqueza nem elementos novos de espécie alguma; e salvo alteração de propriedade no interior do círculo de jogadores, conduz a uma situação idêntica à do início da partida;

5- regulamentada: sujeita a convenções que suspendem as leis normais e que instauram momentaneamente uma legislação nova, a única que conta.

6- fictícia: acompanhada de uma consciência específica de uma realidade outra, ou de uma franca irrealidade em relação à vida normal." (CAILLOIS, 1990, p. 29)

$\mathrm{O}$ autor ainda classifica os jogos em quatro categorias, chamadas funda- 
mentais, composta por Agôn (competição), Alea (sorte), Mimicry (simulacro) e Ilinx (vertigem).

Klaus V. Meier, professor do Departamento de Cinesiologia da Faculdade de Ciências da Saúde da Universidade de Ontário Ocidental (Canadá), afirma em seu texto "On the Inadequacies of Sociological Definitions of Sport" (1981, p. 79), que existem poucas palavras na língua inglesa que comportam multiplicidade de significados convergentes como a palavra "esporte" e o problema em sua definição é um dos temas básicos e extensos da literatura sobre a sociologia do esporte. Além de apresentar e confrontar várias definições de "esporte", sugere (1981, p. 96) uma representação gráfica que busca conceituar as diferenças entre brincadeira, jogo e esporte (FIGURA 1), onde os termos são definidos como:

Brincadeira: qualquer atividade perseguida voluntariamente por recompensas intrínsecas;

Jogo: atividades dirigidas a uma meta, onde as regras limitam os meios admissíveis e proíbem o uso de meios mais eficientes em favor dos menos eficientes e que ao serem aceitas tornam a atividade possível;

Esporte: possui as mesmas características do jogo, porém requerem habilidade física e destreza.

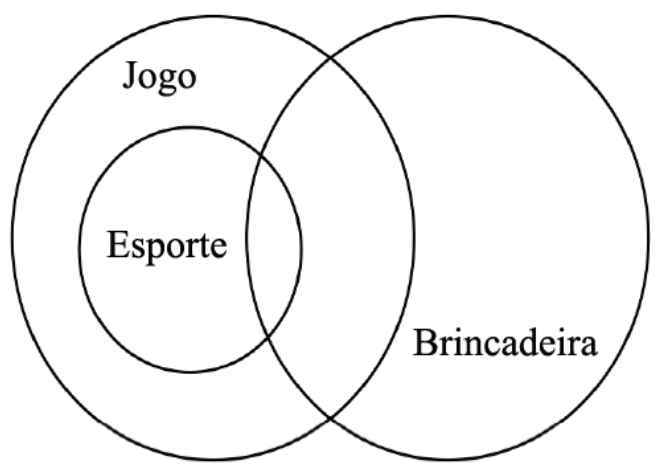

FIGURA 1 - Representação gráfica com as inter-relações entre brincadeira, jogo e esporte (adaptado de MEIER, K.V, 1981, p. 96)
Meier ainda apresenta uma explanação desta representação afirmando que a partir dela podemos concluir que:

Todos os esportes são jogos; nem todos os jogos são esportes; Esportes e jogos podem ou não serem brincadeiras; Esportes e jogos podem ser brincadeiras se buscados voluntariamente para a obtenção de recompensas intrínsecas; Esportes e jogos são não-brincadeiras quando involuntários ou quando a participação é pautada por recompensas extrínsecas; A brincadeira pode assumir formas outras dos jogos e dos esportes. (MEIER, K.V, 1981, p. 96) ${ }^{4}$

Suits (1988) também propõe uma representação gráfica com as inter-relações entre brincadeira, jogo e esporte

(FIGURA 2).

Legenda:

1- Brincadeira primitivas

2- Brincadeiras sofisticadas

3- Jogos profissionais não-atléticos

4- Performances amadoras

5- Esporte amador

6- Esporte profissional

7- Performances atléticas profissionais

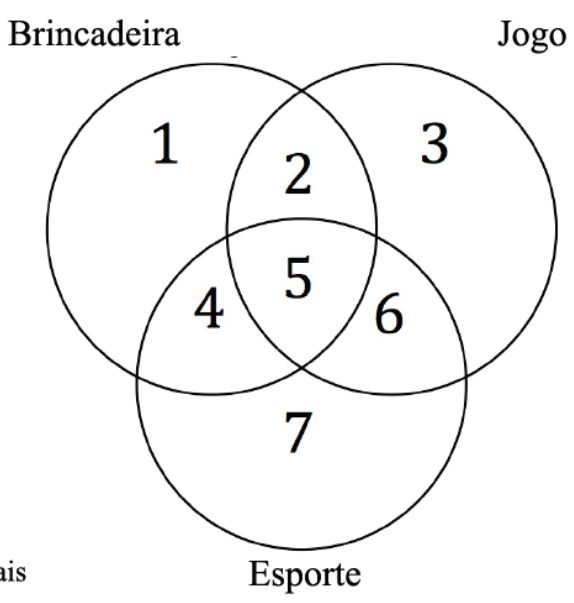

FIGURA 2 - Representação gráfica com as inter-relações entre brincadeira, jogo e esporte proposta e adaptada a partir de SUITS (1988)

Valdir Barbanti, professor titular da Escola de Educação Física e Esporte da Universidade de São Paulo em Ribeirão Preto, afirma em seu texto "O que é esporte?" (2006) que "esporte é uma atividade competitiva institucionalizada que envolve esforço físico vigoroso ou o uso de habilidades motoras relativamente complexas, por indivíduos, cuja participação é motivada por uma combinação de fatores intrínse-
4- No original em inglês: All sports are games, Not all games are sports. Sports and games may or not be play, Sports and games are play if voluntarily pursued for intrinsic rewards, Sports and games are non-play if involuntarily pursued or participated in for extrinsic rewards,

Play may take forms other than sport and games. 
cos e extrínsecos" (BARBANTI, 2006, p. 57).

\section{Game Cultura e E-sports ou Espor- tes Eletrônicos}

Um dos fatos culturais e mercadológicos mais marcantes do desenvolvimento das tecnologias computacionais foi $o$ avanço dos videogames e da game cultura, esta última compreendida como "cultura específica que se apropria de elementos que constituem parte do universo do videogame e seus desdobramentos" (NEVES, 2010), sendo que estes elementos estão circunscritos nas esferas econômicas, social e psicológica e têm potencial para moldar as formas como "determinados grupos se relacionam, convivem e se divertem." $\mathrm{O}$ autor ainda afirma que, historicamente, a

[...] game cultura atinge seu ápice na difusão dos videogames em larga escala. A game cultura também se desenvolve em um ambiente permeado pelas redes de informação e comunicação e se expande não só através dos consoles, mas dos arca-
5- Para melhor compreensão dos conceitos de pervasividade e ubiquidade ver o texto "Da mobilidade a ubiquidade da comunicação" (MAGNONI, A. F.; AFINNI, L. P.; AMÉRICO, M., 2007) 6- No mundo da tecnologia, "evangelizadores" são pessoas que acreditam fortemente em suas ideias e que se tornam disseminadores de suas crenças e perspectivas, notadamente mercadológicas, ou seja, seus pensamentos tem capacidade de influenciar desde pequenos nichos formadores de opinião até grande número de consumidores. Temos como exemplos Steve Jobs da Apple e Bill Gates da Microsoft. des, dos computadores, dos dispositivos móveis, e através da difusão da computação pervasiva e ubíqua ${ }^{5}$, povoando sistemas de comunicação móvel como celulares, até dispositivos portáteis que podem se tornar em centrais de entretenimento.(NEVES, documento eletrônico, 2010)

O conceito de game cultura é recente e provoca acaloradas discussões em diversos meios, notadamente o acadêmico. Para os interessados em avançar no tema é indicado o texto de Shaw (2010), "What Is Video Game Culture? Cultural Studies and Game Studies" onde a autora afirma que a game cultura se apresenta de forma distinta da cultura de massa e promove uma interessante reflexão sobre o conceito através de um levantamento bibliográfico e a partir de uma categorização dos jogadores em
(1) quem joga, (2) como joga e (3) o quê joga.

Com a disseminação da game cultura se desenvolveu de forma intensa entre os jovens a ideia de e-sport ou esportes eletrônicos. Para Wagner (2006), a história do termo $e$-sport, toma corpo no final dos anos 90 do século $\mathrm{XX}$, quando aparece pela primeira vez em um press release da OGA - Online Gamers Association onde o "evangelizador"6 Mat Bettington tece uma comparação entre os esportes eletrônicos e os esportes tradicionais. Em 1999 a discussão sobre o tema foi potencializada pela vã tentativa de obtenção do reconhecimento pelo English Sports Council do Primeiro Campeonato de Computer Gaming do Reino Unido como competição esportiva oficial. O mesmo autor ainda propõe uma definição de e-sport como "uma área de atividades desportivas onde os indivíduos desenvolvem e treinam as habilidades físicas e mentais na utilização das tecnologias de informação e comunicação" e que toma como base as ideias de Tiedemann (2004) que considera o esporte uma atividade cultural onde há o engajamento voluntário de indivíduos que tem por objetivo "desenvolver, treinar e comparar habilidades de importância cultural dentro de um conjunto de regras comuns e sem prejudicar alguém de forma deliberada”. Para Wagner (2006) não existe necessidade de encarar o e-sport como uma área disciplinar que satisfaça uma definição tradicional de esporte e que se deve entendê-lo como um campo de estudos completamente distinto. Assinala que a superestimada questão se as competições de videogames se configuram como esporte ou não é irrelevante para a discussão acadêmica sobre o tema e advoga a favor da criação do que chama de "ciência do e-sport", nascida da "ligação 
natural entre os esportes tradicionais e o e-sport e que vai muito além da argumentação de que este último se refere apenas a um treinamento adequado da coordenação entre olhos e mãos mediada pelos videogames". Esta nova ciência poderia, inclusive, aplicar em seus estudos as abordagens acadêmicas e metodologias emprestadas dos esportes tradicionais. Ainda segundo ao autor, esta abordagem interdisciplinar permitiria compreender o e-sport não apenas como um fato a ser investigado puramente por suas influências sociais e culturais, mas também com potencial para proporcionar avanços em outras áreas não diretamente conectadas aos videogames. Já Maric (2011, p. 6) define e-sport como "uma competição de videogame organizada" e afirma que, assim como os esportes tradicionais, não se trata somente de uma questão de atletas e competição, mas também sobre audiências, fãs e transmissões broadcast, mesmo fato apontado por Saraiva (2013, documento eletrônico) que assinala que "tal como nos desportos tradicionais, o desporto eletrônico atrai uma vasta comunidade de elementos: jogadores, equipes, patrocinadores, fãs e, mais importante, espectadores.” Desta relação surge a importância da mídia no e-sport e a figura do espectador nas transmissões de partidas e eventos competitivos de videogames, definido por Cheung (2012, p. 772), como uma "pessoa cujas intenções variam de assistir uma partida de videogame casualmente até aquelas que se tornam fãs e torcedoras em torneios ou competições de videogame".

Coakley, em seu livro "Sport in society: issues and controversies" (2009, p. 14) considera o esporte uma construção social mutável que não deve privilegiar sistematicamente algumas categorias de pesso- as em detrimento de outras. Portanto, na perspectiva deste autor podemos entender que videogames podem ser considerados esportes na medida em que seu conceito evolui ao longo do tempo.

Colabora ainda para esta ideia, o framework proposto pela disciplina "Fundamentos sociais do esporte e atividade física" da Escola de Cinesiologia da Faculdade de Ciências da Saúde da Universidade de Ontário Ocidental do Canadá (FIGURA 3) onde se aplica a ideia de construção social da experiência esportiva.

\section{Construção social da (minha) experiência esportiva}

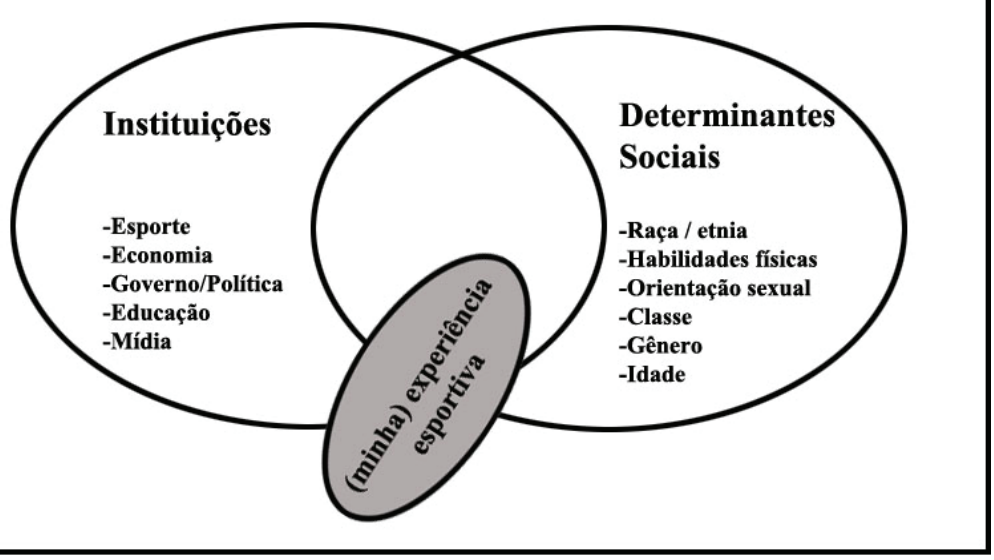

FIGURA 3 - Framework das experiências esportivas cotidianas proposto pela Escola de Cinesiologia da Faculdade de Ciências da Saúde da Universidade de Ontário Ocidental-Canadá. Disponível em: < http://www.uwo.ca/fhs/kin/undergrad/files/courses/ $\underline{K I N \% 202250 A . p d f}>$ Acesso em 02 de setembro de 2014.

Através da aplicação deste framework nas experiências esportivas cotidianas de cada indivíduo é possível refletir sobre o esporte como uma prática socialmente construída que se modifica ao longo do tempo e que habita um novo ecossistema midiático criado na esfera interdisciplinar que engloba esporte, mídia e tecnologia, onde esportes e videogames buscam fundir-se no conceito de e-sport, um fenômeno da cultura digital contemporânea. 


\section{A Plataforma Twitch}

Com mais de 55 milhões de visitantes mensais, Twitch (www.twitch.tv) é a principal comunidade e plataforma mundial de vídeo para gamers. Transmite desde partidas de jogadores que oferecem, via streaming de vídeo, dicas para melhorar o desempenho em determinados games até campeonatos internacionais com importantes patrocínios. Conforme relatório divulgado em junho de $2014^{7}$, a plataforma está em quarto lugar entre as redes de empresas responsáveis pelos maiores picos de tráfego na internet. Em sua página web,

7 Em primeiro lugar está a Netflix com $32 \%$, segundo lugar a Google com $22 \%$, terceiro a Apple com 4,3\% e quarto o Twich com 1,8\%, de acordo com o relatório produzido pela Lifecourse Associates intitulado "The new face of gamers". Disponível em: < http:// twitch.wpengine. com/wp-content/ uploads/2014/06/ TheNewFaceofGamers1.pdf > Acesso em 01 de setembro de 2014. 8- Disponível em: http://www.twitch. tv/p/about. Acesso em 02 de setembro de 2014.

9- Disponível em

$<$ http://dictionary.cambridge. org/dictionary/english-portuguesel twitch_1 $>$ Acesso em 02 de setembro de 2014.

10- Disponível em: $<$ http://dictionary.cambridge. org/dictionary/english-portuguesel twitch $2>$ Acesso em 02 de setembro de 2014. apresenta como objetivos "conectar e possibilitar que jogadores do mundo inteiro possam transmitir, assistir e conversar sobre partidas de videogame onde quer que estejam." ${ }^{3}$ Foi adquirida pela Amazon em agosto de 2014 por 1,1 bilhão de dólares.

A palavra inglesa "twitch" é traduzida em português pelo dicionário Cambridge On Line como "contrair-se" ou "crispar-se", já sua definição como substantivo é "contração muscular", "tique nervoso"10, bem distinta da versão inglês-inglês do mesmo dicionário, onde a palavra é definida como "(causar) ou realizar um pequeno movimento brusco com uma parte do corpo, geralmente sem intenção"11. Já o termo "twitch gameplay", conforme a Wikipédia, é definido "um jogo ou situação que testa o tempo de reação do jogador" ${ }^{12}$. Outra definição é aquela encontrada no exclusivo universo dos "gamers" em comunidades e fóruns de jogadores. Um exemplo é a proposta pelo fórum Atari $A g e^{13}$ onde é definido como "jogos onde é preciso reagir imediatamente às ações e que não exigem estratégia ou padrões de memorização". Assim o nome da plataforma descreve um jargão do universo dos gamers que demonstra a necessidade de habilidades físicas específicas para a prática do videogame.

De acordo com Lemos (2014, documento eletrônico), é notável o poder de penetração deste meio híbrido entre TV, videogames, internet e redes sociais e destaca a audiência da plataforma que em determinados momentos pode superar a de muitos canais a cabo em território americano e afirma que (para o Twitch):

É comum o site ultrapassar a CNN, o E! e até mesmo a rede MSNBC em espectadores. Atualmente, ele chega a ter picos próximos da audiência da MTV americana. Um dia típico no Twitch consiste em milhares de jogadores transmitindo suas partidas de casa. Há também campeonatos de títulos como "Counter Strike" ou "League of Legends", que contam com narradores e comentadores, no melhor estilo Galvão Bueno. $\mathrm{O}$ site abriga também ligas esportivas de diversos jogos, que crescem e se profissionalizam tais como as ligas dos esportes tradicionais. Em síntese, o Twitch virou um grande negócio. E, para comprá-lo, a Amazon enfrentou uma disputa acirrada com o Google, que perdeu no último lance. (LEMOS, 2014, documento eletrônico $)^{14}$

O Twitch também tem canais específicos para os usuários brasileiros e em uma visita ao site ${ }^{15}$ foi notada a seguinte audiência para a transmissão de partidas ao vivo dos respectivos videogames: League of Legends: 167.525 espectadores; Counter-Strike: Global Offensive: 27.200 espectadores e Destiny: 23.497 espectadores. Estes índices são significativos e caso o evento fosse veiculado por uma emissora de TV aberta brasileira, a transmissão com maior público teria quase três pontos de audiência em uma hipotética aferição do IBOPE, onde cada ponto significa 60.000 domicílios na cidade de São Paulo, ou seja, um valor 
importante para uma transmissão de uma partida ou campeonato de videogame. Em outra transmissão realizada no mesmo dia, relativa à "Copa América de Starcraft", evento para toda América Latina, o total de espectadores conectados chegou ao incrível número de 836.928 .

Um fato importante do ponto de vista do jornalismo esportivo é que o Twitch se apropria da lógica e da linguagem das transmissões de eventos esportivos de canais de TV como Sportv, ESPN e Fox Sports, adequando-se para adeptos, fãs e espectadores de eventos esportivos eletrônicos. Desta forma, nas transmissões existem locutores, comentaristas, repórteres e público, assim como qualquer grande evento esportivo tradicional (Figura 4). mente impregnado na vida das pessoas do que o mercado de consumo consegue alcançar. (GASTALDO, 2012, p.131-132)

Em plena era da convergência dos meios, o desenvolvimento dos dispositivos digitais conectados em rede potencializa a presença do elemento lúdico em nossa cultura. Através do desenvolvimento tecnológico acentuado a partir das duas últimas décadas do século XX ocorrem mudanças nos produtos de entretenimento que demandam novas habilidades por parte daqueles que ainda não perceberam que não se trata mais de produto de uma cultura de massa tradicional. $\mathrm{O}$ entretenimento deixou de ser apenas "sensorial" numa simples oposição à atividade inte-

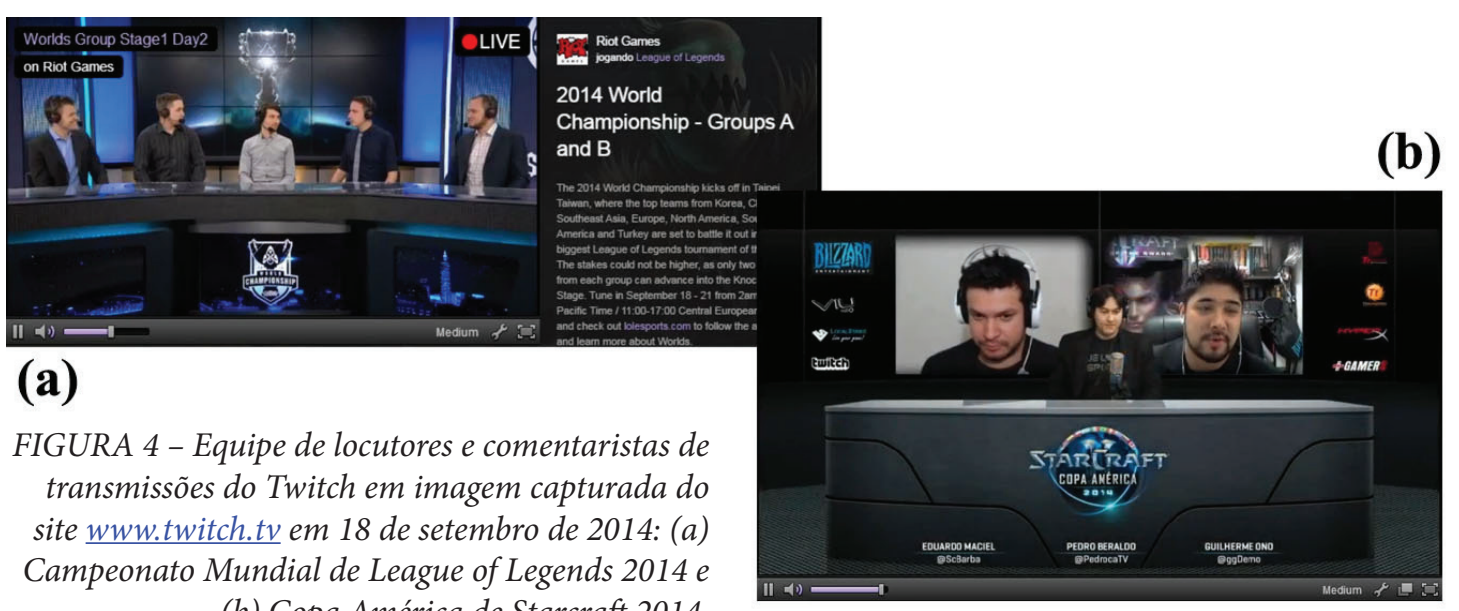

(b) Copa América de Starcraft 2014.

\section{Considerações Finais}

Huizinga não viveu o suficiente para ver a indústria contemporânea dos jogos eletrônicos, dos videogames e aplicativos lúdicos para smartphones, tablets e PCs. Mas não se teria surpreendido em ver que, quanto mais esforço fazemos para expurgar o "espírito do jogo" de nossas atividades "sérias", mais ele nos cerca e povoa o mundo com "diversões" e "espetáculos", oferecidos por uma indústria que faz da produção de lazer o seu trabalho. [...]Entretanto, passados mais de setenta anos, acreditamos que o princípio lúdico da Humanidade está mais profunda- lectual e passou a exigir além do exercício mental a ação do corpo e de formas cognitivas antes desnecessárias. Portanto, as mídias digitais revolucionaram a indústria do entretenimento, proporcionando um novo paradigma em suas formas de recepção. Estes câmbios chegam agora ao âmbito do esporte e promovem recuperação e revisão de conceitos como de brincadeira, jogo, do próprio esporte e suas relações com o jornalismo.

Surge, desta forma, o conceito de $e$ -sport, ou esporte eletrônico que se apre-
11- Em Inglês: "(to cause) to make a sudden small movement with a part of the body, usually without intending to." Disponível em: $<$ http://dictionary. cambridge.org/dictionary/ american-english/twitch > Acesso em 02 de setembro de 2014.

12- Disponível em < http:// en.wikipedia.org/wiki/Twitch gameplay $>$ Acesso em 02 de setembro de 2014. 12- Disponível em: < http://atariage.com/forums/topic/209244-what-is-the-strict-definition-of-a-twitch-game/http:// atariage.com/forums/ topic/209244-what-is-the-strict-definition-of- $a$ -twitch-gamel > Acesso em 02 de setembro de 2014.

14- Cf. matéria veiculada no Jornal Folha de São Paulo em 02/09/2014 intitulada "Videogame como programa de $T V$ " de Ronaldo Lemos. Disponível em: < http:// wwwl.folha.uol.com.br/colunas ronaldolemos/2014/09/1509232 -videogame-como-programa-de-tv shtml $>$ Acesso em 01 de setembro
de2014. 15- Realizada em 18 de setembro de 2014, quinta-feira, às 21horas. 
senta por uma apropriação pela juventude da categoria fundamental de jogo definida por Callois como "mimicry", ou seja, aquela ligada à simulação e que compreendem os jogos de imitação onde o jogador "despoja-se temporariamente de sua personalidade para fingir outra" (CALLOIS, 1990, p. 40), ou seja, se apropria de outra realidade que não a sua. Esta mesma juventude compreende, como afirma Cakley (2009), o esporte como uma prática socialmente construída que se modifica ao longo do tempo e o conceito de $e$-sport se apresenta como uma construção baseada na experiência esportiva desta comunidade.

Não é tarefa simples apreender o papel do jornalismo esportivo transmídia no ecossistema dos esportes eletrônicos ( $e$ -sports), portanto, a primeira etapa para aceitar estas relações interdisciplinares necessárias para (re)pensar a formação e papel do jornalista em um ambiente em transformação é compreender conceitos e aplicá-los à prática profissional. Já vigora a ideia de "jornalismo" e não mais "jornalismo digital". Em pouco tempo, “jornalismo transmídia" será reconhecido como simplesmente "jornalismo", assim como não parece fazer muito sentido segmentar a atividade jornalística em mídias (impressa, radiofônica, televisual, fotográfica, etc). Volta-se apenas a pensar em "fotografia" e não "fotografia digital" e o mesmo acontecerá com outros processos atrelados à convergência dos meios, como "televisão" em vez de "televisão digital", "rádio" em vez de "rádio digital". Este é o princípio da Ecologia dos Meios, onde existem comportamentos e tecnologias que se acomo- dam ou ajustam aos novos ambientes. A plataforma Twitch mostra que o conceito de esporte eletrônico é uma variação adaptada dos conceitos de jogo e esporte tradicional (aqui apresentados) e deve ser pensada como um fenômeno da cultura digital contemporânea que entende o esporte como uma prática socialmente construída que se modifica ao longo do tempo, como apontado por Coakley (2009). A mesma plataforma, como demonstrado, se apropria da lógica e da linguagem das transmissões de eventos esportivos de canais de TV voltados para o esporte adequando-as para praticantes assim como os recém-descobertos espectadores de partidas de videogames. Logo, faz-se mister para o universo jornalístico perceber que dentro destas transmissões de eventos de esportes eletrônicos existe, de forma natural, um espaço de atuação para profissionais da área em um mercado que de fato, como demonstrado, já existe. Desta forma é importante refletir sobre o esporte como uma prática socialmente construída que se modifica ao longo do tempo e que habita um novo ecossistema midiático criado na esfera interdisciplinar que engloba esporte, mídia e tecnologia, onde esportes e videogames buscam fundir-se no conceito de e-sport, um fenômeno da cultura digital contemporânea. O ecossistema do jornalismo esportivo é habitado por repórteres, locutores, comentaristas, cronistas e demais atores envolvidos na transmissão, divulgação e crítica de eventos esportivos, mesmo que estes eventos sejam denominados "esportes eletrônicos". 


\section{Referências bibliográficas}

BARBANTI, Valdir José . O que é esporte? Revista Brasileira de Atividade Física e Saúde, v. 2, p. 54-58, 2006.

CAILLOIS, Roger. Os jogos e os homens. Lisboa: Cotovia, 1990.

CHEUNG, Gifford, HUANG, Jeff. Starcraft from the stands: understanding the game spectator. Proceedings of the SIGCHI Conference on Human Factors in Computing Systems, May 07-12, 2011, Vancouver, BC, Canada [doi>10.1145/1978942.1979053]. Disponível em: < http://dl.acm.org/citation.cfm?id=1979053 $>$ Acesso em 15 de setembro de 2014.

COAKLEY, J. Sport in society: issues and controversies. New York: McGraw-Hill, 2009. GASTALDO, Édison. Homo Ludens e o Esporte Moderno. In: Esportes na Idade Mídia: diversão, informação e educação. Marques, José Carlos ; Morais, Osvando J. de (orgs). P 125-136. São Paulo: INTERCOM, 2012

HUIZINGA, J. Homo ludens. São Paulo: Perspectiva, 2000.

JENKINS, Henry. Cultura da convergência. São Paulo: Aleph, 2008.

LEMOS, R. "VideogamecomoprogramadeTV”. JornalFolhadeSãoPaulo, 02/09/2014.Disponível em: < http://www1.folha.uol.com.br/colunas/ronaldolemos/2014/09/1509232-videogame-como-programa-de-tv.shtml > Acesso em 01 de setembro de2014.

LIFECOURSE ASSOCIATES. The new face of gamers. Disponível em: $<$ http://twitch. wpengine.com/wp-content/uploads/2014/06/TheNewFaceofGamers1.pdf $>$ Acesso em 01 de setembro de 2014.

MEIER K. V. On the Inadequacies of Sociological Definitions of Sport. International Review for the Sociology of Sport June 1981 16: 79-102, doi:10.1177/101269028101600206 MAGNONI, A. F.; AFINNI, L. P.; AMÉRICO, M. Da mobilidade a ubiqüidade da comunicação. In: Anais do XXX Congresso Brasileiro de Ciências da Comunicação - Santos - 29 de agosto a 2 de setembro de 2007. Disponível em: < http://www.intercom.org.br/ papers/nacionais/2007/resumos/R0811-2.pdf $>$ Acesso em 03 de setembro de 2014.

MARIC, J. Electronic Sport: How pro-gaming negotiates territorial belonging and gender. PLATFORM: Journal of Media and Communication, YECREA Special Issue November: 6-23. ISSN: 1836-5132, 2011. Disponível em: < http://journals.culturecommunication.unimelb.edu.au/platform/yecrea 2011 maric.html $>$.Acesso em 01 de setembro de 2014.

NEVES, F. Participatory Culture e Gamecultura. 2010, disponível em: < http://www. gamecultura.com.br/index.php/midia/textosfp/gamecultura/199-culture $>$ Acesso em 03 de setembro de 2014.

NYSTROM, C. L. Toward a science of media ecology: The formulation of integrated conceptual paradigms for the study of human communication systems. 1973. Tese de Doutorado. New York University, School of Education.

What is Media Ecology? Disponível em $:<$ http://www.media-ecology.org/media ecology/index.html $>$. Acesso em 03 de agosto de 2014.

POSTMAN, Neil. The humanism of media ecology. In: Proceedings of the Media Ecol326 
ogy Association. 2000. p. 10-16. Disponível em: $<$ http://w.media-ecology.org/publications/MEA proceedings/v1/postman01.pdf $>$ Acesso em 08 de outubro de 2013.

, The Reformed English Curriculum. in. EURICH, Alvin Christian

(Ed.). High school 1980: the shape of the future in American secondary education. Pitman Pub. Corp., 1970.

RENÓ, Denis P. ; RENÓ, Luciana Tarlá Lorenzi . Linguagens e interfaces para o jornalismo transmídia. In: João Canavilhas. (Org.). Notícias e mobilidade: jornalismo na era dos dispositivos móveis. 1ed.Covilhã: Livros Labcom, 2013, v. 1, p. 55-70.

SANTAELLA, Lucia. A ecologia pluralista da Comunicação: conectividade, mobilidade, ubiquidade. São Paulo: Paulus, 2010.

SARAIVA, P. E-sports: Um Fenómeno da Cultura Digital Contemporânea. Videojogos 2013 - Conferência de Ciências e Artes dos Videojogos, Departamento de Eng. Informática, Universidade de Coimbra, Portugal Disponível em: < http://vj2013.dei.uc.pt/ wp-content/uploads/2013/09/vj2013 submission 12.pdf $>$ Acesso em 02 de setembro de 2014.

SCOLARI, C. A. (2012). Media Ecology: Exploring the Metaphor to Expand the Theory. Communication Theory, 22 (2012), 204-225. Disponível em: < http://onlinelibrary.wiley.com/doi/10.1111/j.1468-2885.2012.01404.x/pdf $>$ Acesso em 08 de outubro de 2013. SHAW, Adrienne. What is video game culture? Cultural studies and game studies. Games and culture, v. 5, n. 4, p. 403-424, 2010. Disponível em: < http://gac.sagepub.com/ content/5/4/403.full.pdf + html $>$ Acesso em 02 de setembro de 2014.

SILVA, Marco. Interatividade: uma mudança fundamental do esquema clássico da comunicação. Boletim Técnico do SENAC, Rio de Janeiro, v. 23, n. 3, p. 19-27, 2000. Disponível em: < http://www.senac.br/informativo/bts/263/boltec263c.htm $>$ Acesso em 02 de setembro de 2014.

STRATE, L. Understanding mea. medias res, v. 1, n. 1, 1999.

Studying media as media: McLuhan and the media ecology approach. Me-

dia Tropes eJournal, 1, p. 127-142. 2008. Disponível em: < http://fordham.bepress.com/ comm facultypubs/9/ > Acesso em 12 de setembro de 2014.

SUITS, B. Tricky triad: games, play and sport. Journal of the Philosophy of Sport, 1988, $15, \mathrm{p} 1-10$.

TAPSCOTT, D. Geração digital: a crescente e irreversível ascensão da geração net. São Paulo: Makron Books, 1999.

TIEDEMANN, C. Sport (and culture of physical motion) for historians, an approach to precise the central term(s). Proc. IX International CESH-Congress, Crotone, Itália, 2004. WAGNER, M.G. On the Scientific Relevance of eSports. Proc. International Conference of Internet Computing, 2006, p. 37-442. Disponível em: < http://ww1.ucmss.com/ books/LFS/CSREA2006/ICM4205.pdf > Acesso em 02 de setembro de 2014.

Estudos em Jornalismo e Mídia está sob a Licença Creative Commons 2.5 